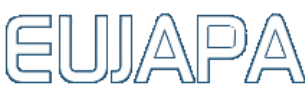

Article

\section{Sequential analysis of the construction of shots in wheelchair basketball and efficiency by player classification level}

Roberto Alsasua $^{1}$, Rubén Arroyo ${ }^{2}$, Javier Arana ${ }^{3}$, Daniel Lapresa ${ }^{4 *}$ and M. Teresa Anguera ${ }^{5}$ Received: $28^{\text {th }}$ July 2020; Accepted: $16^{\text {th }}$ December 2020; Published: $24^{\text {th }}$ August 2021

\begin{abstract}
The objective of the present study was to analyse the construction and effectiveness of the offensive sequences of shots by members of the 2016 Paralympic gold medal men's wheelchair basketball team. The analysis included the shot situation and of the actions leading up to the shot (reception prior to the shot, last pass, reception prior to the last pass, penultimate pass, and previous reception to the penultimate pass), based on the classification level of the player who performs the technical-tactical action. The registration and coding of the data was performed on the software programme LINCE. The reliability of the data was examined by inter-observer agreement through Cohen's Kappa coefficient. The results allow to deepen the specificity of the game of this sport, having characterized the construction of effective and ineffective (shot from the right lateral or the centre; from the offensive outside or from the offensive intermediate zone; shot made by players with the greatest functional limitations; players with greater functional difficulties perform the last reception, the last pass, and the reception prior to the last pass) sequences.
\end{abstract}

Keywords: match analysis; functional abilities; observational methodology; lag sequential analysis

\section{Introduction}

Wheelchair basketball is one of the adapted sports with the highest number of federative licenses (International Wheelchair Basketball Federation, 2017). In wheelchair basketball, the regulations are similar to original basketball, except in relation to the issue of functional classification that allows people with different types of disabilities to share a court. Even people who are non-wheelchair users can be found playing the sport during their day to day (Palau et al., 2011). The functional classification in wheelchair basketball is based on the player's ability to carry out the actions of the game: move the chair, pivot, shot to basket, bounce, etc. (International Wheelchair Basketball Federation, 2014). In this way, the different functional limitations presented by the players influence the ability to execute the different skills put into play (de Witte et al., 2016; Molik et al., 2017).

All wheelchair basketball players with impairments are categorized into one of the eight existing classification levels (1.0, 1.5, 2.0, 2.5, 3.0, 3.5, 4.0 and 4.5) after evaluation. By way of an example and to clarify, a level 1.o player (the one with the greatest limitation) is one who has little or no controlled movement of the trunk in the frontal plane. Moreover, a 1.0 player someone who does not have the capacity to actively rotate the trunk, has significantly affected balance in the frontal and lateral directions, and needs their arms to return to the 
vertical position if in an unbalanced situation. At the opposite extreme; a level 4.5 player (the one with lesser limitation) can move the trunk normally in all directions and is able to tilt the trunk to one side and the other without limitations (International Wheelchair Basketball Federation, 2014). In a wheelchair basketball game, the sum of the classification levels of the five players on a team who are on the court cannot exceed 14 points; however, it is allowed to play with a lower score (International Wheelchair Basketball Federation, 2017).

Currently, wheelchair basketball is one of the adapted sports studied by researchers from different fields such as: physiology (Antonelli et al., 2020; Barboza et al., 2019; Conners et al., 2020; Feter et al., 2018; Galea et al., 2018; Marzsalek et al., 2019; Peters et al., 2020), biomechanics (de Witte et al., 2016; Marjolaine et al., 2018; Sasadai et al., 2020; Zacharakis, 2020), medicine (Hollander et al. 2020), motor skills (Maksym et al. 2018; de Witte et al., 2018), psychology (Qasim et al., 2019; Yeats et al., 2019), or sociology (Molik et al., 2017).

Match analysis has also been carried out in the field of wheelchair basketball (Francis et al., 2019a, 2019b; Gómez et al., 2014; Mason et al., 2018; Pérez-Tejero \& Pinilla, 2015; PérezTejero et al., 2020), in which the analysis of the effectiveness of the game is carried out in the manner of elite basketball (Alsasua et al., 2018; Troyano et al., 2018). As in basketball, shooting is the way to obtain points, the success of the shot becomes a key aspect in the analysis of the effectiveness of the game. This efficacy analysis is performed in the majority of studies using conventional statistical analysis based on the frequency parameter. But to obtain a deeper knowledge of the game, it is necessary to overcome the usual synchronous statistical analysis in notational studies and study game actions diachronically, under the order or duration parameter (Anguera, et al., 2021). Lag sequential analysis is one of the diachronic analysis techniques that allows detecting the existence of regular patterns of behaviour hidden in the registry (Bakeman \& Quera, 1995, 2011). However, none of these previous wheelchair basketball works has carried out analyses of efficacy through a lag sequential analysis (Bakeman, 1978). Diachronic results have been performed on elite basketball and are highly relevant to the analysis of the game (Fernándezet al., 2009; Nunes et al., 2015). Furthermore, the player's classification level has not been incorporated into the technical-tactical actions constituting a diachronic record (Anguera, 2003).

The objective of the present study is to analyse the construction and effectiveness of the offensive sequences in wheelchair basketball shots. The sequence takes into account the situation of the shot, the reception prior to the shot, the last pass, the previous reception, the last pass, the penultimate pass, and the reception prior to the penultimate pass. All of this is based on the classification level of the player, who performs the technical-tactical action.

\section{Materials and Methods}

The present study is situated in the line of match analysis using observational methodology (Anguera, 1979; Lapresa et al., 2017). The observational design (Anguera et al., 2011) was idiographic, punctual, and multidimensional. It is idiographic because the analysis are based on the performance of a single team, the winner of the tournament. It is punctual because it studies the participation of the USA team in the Paralympic Games in Rio de Janeiro 2016, and it has also intra-sessional follow-up (Anguera et al., 2021), because each sequence of behaviours finished when a shot was produced in that match. Furthermore, it is multidimensional because multiple dimensions are studied, which are the proxemic dimensions (related to the areas of the court where the actions take place) and the gestural dimensions (where the different technical-tactical actions developed by the players in the offensive phase of the game are displayed). 


\section{Participants}

The observational sampling of this study was made up from the USA men's wheelchair basketball team and all the sequences leading up to a shot. The number (fixed) of the players and their classification levels were identified was: players 12 and 13 (class 1.0), player 42 (class 2.0), players 2, 16 and 20 (class 2.5), player 5 (class 3.0), players 4, 9 and 11 (class 3.5), and players 8 and 15 (class 4.5) (Results Book of Wheelchair Basketball Competitions, 2016 Paralympic Games). The distribution of the positions of these players, based on their classification levels, is in line with that found in the scientific literature (de Witte et al., 2016; Vanlandewijck et al., 2003; Vanlandewijck et al., 2004), so that the classification levels 1.0 and 1.5 play as point guards, 2.0 and 2.5 as small forwards and 4.0 and 4.5 assume the centre role.

Filming of all matches was obtained from the open video channel of the International Paralympic Committee (https://www.youtube.com/user/ParalympicSportTV). This work has the relevant informed consents and the approval of the Research Ethics Committee of the University of La Rioja (file $\mathrm{n}^{0}$ 25238).

\section{Observation instrument}

In this study, the observation instrument that Alsasua and colleagues (2019) developed from the observation system in basketball prepared by Fernández and colleagues (2009) was adapted. Specifically, the adaptation (Table 1) has consisted of the introduction of the player's classification level criteria.

\section{Recording and coding}

The recording and coding of the data, incorporated 525 sequences that led to a shot, was been developed using the LINCE software (Gabin et al., 2012). According to the classical typology of Bakeman (1978), the data obtained are type IV, concurrent and time-base. Also, according to the new data typology coined by Bakeman and Quera (1995), for the development of the GSEQ software, the data type is multi-event sequential, consequently with the fact that the observational design is multidimensional. Each "game action" results in a new row of the record or multi-event that incorporates the information of the corresponding dimensions. The records obtained in the LINCE program were automatically exported by LINCE for subsequent analysis in GSEQ5 as type II data. As a guideline for researchers or technical personnel, the recording of the offensive sequences that lead to a shot taken took an average of 3 hours per game.

\section{Data reliability}

Two observers were in charge of recording the data that supports the present study. The first of them recorded the entire observational sampling; the second observer recorded 10\% of the sequences corresponding to each match, starting from the beginning of the match. The observer training process was carried out, in three phases, following the proposal made by Arana and colleagues (2016), originally from Anguera (2003): 1) Theoretical training in the observation instrument; 2) Theoretical-practical training: in relation to the registration procedure, the observation instrument has always been inserted in the LINCE record and coding instrument; 3) Practical training: autonomous registration of observers from a nonsampling observation session; after obtaining a high degree of agreement (Cohen's Kappa > o.80) among the observers, the training process was terminated. Taking into account the classic reference values of Landis and Koch (1977, p. 165), the results corresponding to Cohen's Kappa (1960) that reflect the agreement of the records corresponding to each match (Brazil-USA, 0.889; USA-Germany, 0.888; USA-Iran, 0.910; Algeria-USA, 0.891; USA- 
Great Britain, 0.883; USA-Netherlands, 0.877; Turkey-USA, 0.913; Spain-USA, 0.936) get an agreement consideration of "almost-perfect".

Table 1. Observation instrument

\begin{tabular}{ll|l|l|}
\hline Dimension & Category (codes) \\
\hline Laterality & Offensive lateral right (OLR); Right bottom offensive (RBO); Offensive centre \\
(OC); Offensive lateral left (OLL); Left bottom offensive (LBO); Defensive \\
lateral right (DLR); Right bottom defensive (RBD); Defensive centre (DC); \\
Defensive lateral left (DLL); Left bottom defensive (LBD)
\end{tabular}

\section{Data analysis}

Lag sequential analysis (Bakeman, 1978) is greatly facilitated in the GSEQ software (Bakeman \& Quera, 1995, 2011). This software allowed the calculation of the adjusted residuals between criterion or given behaviours and conditioned behaviours or target behaviours as well as the subsequent interpretation of the statistically significant differences between the conditioned (from the observed frequencies) and unconditional probabilities (from the expected frequencies), in the successive lags contemplated. GSEQ is mainly used in studies with sequential multievent data (as is the case in this study) (Tarragó et al., 2017).

The calculation of the adjusted residuals allowed to contrast in the strength of the association between categories. According to Bakeman and Quera (2011), the adjusted residual is positive if the observed frequency is greater than chance and negative if it is less than chance. According to Bakeman and Gottman (1986), transitions greater than or equal to $1.96(\mathrm{p}<0.05)$, represent a greater probability of occurrence than expected by chance (activation relationship between criterion and conditioned behaviour); and transitions less than or equal to -1.96 ( $\mathrm{p}<0.05$ ), represent a lower probability of occurrence than expected by chance (inhibition relationship between criterion and conditioned behaviour). 
The calculation of the adjusted residuals has been carried out taking into account a) the logic of the observation instrument: each of these sequences consists of the shot and up to a maximum of five previous actions, six rows of the record including the shot; and b) that according to Lapresa et al. (2013), from the lag -5 (and +5 ) the sequential patterns of behaviour seem to dilute. In this way, the following has been analysed: lag o or co-occurrence (the row of the record corresponding to a shot to the basket); the five behaviours that occur before the criterion behaviour (five rows of the previous record) as the retrospective perspective.

\section{Results}

In all the analyses carried out, the categories corresponding to the dimension "consequence of completion" have been established as criteria or given categories. In this way, we have proceeded to detect statistically significant relationships of activation (transitions greater than or equal to 1.96) or inhibition (transitions less than or equal to 1.96), which are shown in Tables 2, 3, 4 and 5. In the left column the criteria or given behaviours (corresponding to the consequence of completion criterion) are presented, and in the upper row the conditioned or target behaviours (corresponding to the Laterality, Zone, Classification level, Game action and Start of the sequence criteria). In the corresponding cells, the lag is first detailed ( $\mathrm{LO}=$ row of the record corresponding to completion; $\mathrm{L}-1=\mathrm{lag}$ 1, corresponds to the row before completion; L-2, two rows before, etc); and then, in parentheses, the value of the significant adjusted residual corresponding to said lag is presented. Negative adjusted residuals have been underlined which, instead of activation or association relationships, imply inhibitory relationships between associated behaviours.

It should be noted that in the sequential analysis lag -1 is related to the reception prior to the shot (conditional probability $=0.91$ ), lag -2 with the last pass (conditional probability $=1$ ), lag -3 with the penultimate reception (conditional probability $=0.83$ ), and lag -4 with the penultimate pass (conditional probability=0.86).

Regarding the analysis of the laterality dimension (see Table 2) and with respect to effective sequences, the shot from the right laterality of the offensive bottom inhibits (in a statistically significant way) the achievement of error (MS-RBO, LO=-3.90) and favours obtaining favourable consequences such as a foul received $(\mathrm{RF}-\mathrm{RBO}, \mathrm{LO}=2.12)$ or a score with an additional shot (A1-RBO, LO=2.39). Regarding ineffective sequences, the shot from the offensive lateral right (MS-OLR, Lo=2.72) or from the offensive centre (MS-OC, $\mathrm{LO}=3.93$ ) significantly favours the error. In addition, making a shot from the offensive centre inhibits the scored shot (SC-OC, $\mathrm{LO}=-2.48$ ).

Regarding the analysis of the contingency tables corresponding to retrospective lags, a statistically significant relationship was found, in lag -2, between the dimensions corresponding to Completion type and Laterality $\left(\chi^{2}=73 ; \mathrm{df}=54 ; \mathrm{p}=0.04\right)$. The use of the right bottom area in the reception prior to shooting has been characterized as an effective situation for obtaining a score (MS-RBO, L-1=-3.84; SC-RBO, L-1=2.57; A1-RBO, L-1=2.42) as well as in the reception prior to the last pass (A1-RBO, L-3=2.03). However, the next situations have been characterized as an ineffective situation of the execution in the offensive bottom left area: the last reception (DB-LBO, L-1=2.10) (VI-LBO, L-1=1.98); the penultimate pass (SC-LBO, L-4=-2.28) (MS-LBO, L-4=2.53); and the last pass (VI-LBO, L-2=2.63). Ineffective sequences were detected when the last reception takes place in the offensive centre (MS-OC, L-1=2.14). Effective sequences were found on the defensive right side (A1DLR, L-1=2.90; A1-DLR, L-2=2.02; A1-DLR, L-3=3.50); the defensive centre (A1-DC-, L2=2.49; MS-DC, L-3=-2.40; MS-DC, L-4=-2.30; RF-DC, L -4=-2.58); and the defensive bottom left (SC-LBD, L-3=2.31; MS-LBD, L-3=-2.13). And ineffective sequences, in the defensive bottom left (DB-LBD, L-2=2.80), the defensive lateral right (DB-DLR, L-2=2.26), 
the defensive lateral left (FA-DLL, L-3=3.06) and the defensive bottom right (DB-RBD, L$3=3.52)$.

Table 2. Lag sequential analysis between the given categories of the Consequence of completion dimension and the target behaviours corresponding to the Laterality dimension.

\begin{tabular}{|c|c|c|c|c|c|c|c|c|c|c|}
\hline & OLR & RBO & $\mathrm{OC}$ & OLL & LBO & RBD & $\mathrm{DC}$ & DLL & LBD & DLR \\
\hline $\mathrm{SC}$ & & $\begin{array}{l}\mathrm{L}-1 \\
(2.57)\end{array}$ & $\begin{array}{l}\text { L0 } \\
(-2.48)\end{array}$ & & $\begin{array}{l}\mathrm{L}-4 \\
(-2.28)\end{array}$ & & $\begin{array}{l}\mathrm{L}-5 \\
(2.41)\end{array}$ & $\begin{array}{l}\mathrm{L}-5 \\
(2.04)\end{array}$ & $\begin{array}{l}\mathrm{L}-3 \\
(2.31)\end{array}$ & \\
\hline MS & $\begin{array}{l}\text { L0 } \\
(2.72)\end{array}$ & $\begin{array}{l}\text { L-1 } \\
(-3.84) \\
\text { L0 } \\
(-3.9)\end{array}$ & $\begin{array}{l}\text { L-1 } \\
(2.14) \\
\text { L0 } \\
(3.93)\end{array}$ & & $\begin{array}{l}\mathrm{L}-5 \\
(2.39) \\
\mathrm{L}-4 \\
(2.53)\end{array}$ & & $\begin{array}{l}\mathrm{L}-5 \\
(-2.63) \\
\mathrm{L}-4 \\
(-2.30) \\
\mathrm{L}-3 \\
(-2.04)\end{array}$ & & $\begin{array}{l}\text { L-3 } \\
(-2.13)\end{array}$ & \\
\hline $\mathrm{RF}$ & & $\begin{array}{l}\text { L0 } \\
(2.12)\end{array}$ & & & & & $\begin{array}{l}\mathrm{L}-4 \\
(2.58)\end{array}$ & & & $\begin{array}{l}\mathrm{L}-5 \\
(2.49) \\
\end{array}$ \\
\hline FA & & $\begin{array}{l}\text { L0 } \\
(2.10)\end{array}$ & & & & & $\begin{array}{l}\mathrm{L}-4 \\
(2.99)\end{array}$ & $\begin{array}{l}\text { L-3 } \\
(3.06)\end{array}$ & & \\
\hline VI & $\begin{array}{l}\text { L-4 } \\
(2.33)\end{array}$ & & & $\begin{array}{l}\text { L-3 } \\
(2.36)\end{array}$ & $\begin{array}{l}\mathrm{L}-2 \\
(2.63) \\
\mathrm{L}-1 \\
(1.98)\end{array}$ & & & & & \\
\hline $\mathrm{DB}$ & & & & & $\begin{array}{l}\mathrm{L}-1 \\
(2.10)\end{array}$ & $\begin{array}{l}\mathrm{L}-3 \\
(3.52)\end{array}$ & & & $\begin{array}{l}\mathrm{L}-2 \\
(2.80)\end{array}$ & $\begin{array}{l}\mathrm{L}-2 \\
(2.26) \\
\end{array}$ \\
\hline A1 & & $\begin{array}{l}\text { L-3 } \\
(2.03) \\
\text { L-1 } \\
(2.42) \\
\text { L0 } \\
(2.39)\end{array}$ & & & & & $\begin{array}{l}\mathrm{L}-2 \\
(2.49)\end{array}$ & & & $\begin{array}{l}\text { L-3 } \\
(3.50) \\
\text { L-2 } \\
(2.02) \\
\text { L-1 } \\
(2.90)\end{array}$ \\
\hline
\end{tabular}

Score (SC); Mistake (MS); Received foul (RF); Foul in attack (FA); Violation (VI); Direct block (DB); Basket and Foul (A1). In the top row are the target behaviours: Offensive lateral right (OLR); Right bottom offensive (RBO); Offensive centre (OC); Offensive lateral left (OLL); Left bottom offensive (LBO); Right bottom defensive (RBD); Defensive centre (DC); Defensive lateral left (DLL); Left bottom defensive (LBD); Defensive lateral right (DLR). Negative adjusted residuals that imply inhibitory relationships between associated behaviours are underlined

Regarding the analysis of the zone dimension (see Table 3), those sequences in which the shot is carried out from the paint have been characterized as effective sequences (RF-OP, $\mathrm{LO}=3.96$; A1-OP, Lo=2.77; MS-OP, Lo=-4.36). Regarding ineffective sequences, the shot from the offensive outside (MS-OO, $\mathrm{LO}=3.01$ ) or from the offensive intermediate zone (MS$\mathrm{OZ}, \mathrm{LO}=2.57$ ) significantly favours failure in the shot. In addition, the shot from the offensive intermediate zone inhibits the possibilities of receiving a foul in favour (RF-OZ, LO=-2.90) and a foul after scoring (A1-OZ, LO=-2.02).

Regarding the retrospective analysis of the Zone dimension and with respect to effective sequences, paint as an effective place for shooting (MS-OP-, L-1=-2.86; A1-OP, L-1=2.95) has been detected in lag -1, although there is also an association with receiving a Direct block at the shot (DB-OZ, L-1=-2.12); and the intermediate zone as a usually ineffective place (MS$\mathrm{OZ}, \mathrm{L}-1=2.59$; A1-OZ, L-1=-2.41). Effective and ineffective sequences have also been detected in which the defensive field is present in relation to the zone dimension: during the last pass, the association between defensive outside (RF-DO, L-2=2.10) with foul received was detected; while from the defensive intermediate zone it presents effective (A1-DZ, L-2=2.52) and ineffective (DBDZ, L-2=2.80; FA-DZ, L-3=2.18) situations; and the defensive paint (DB-DP, L-1=2.26; DB-DP, L$3=2.41$; FA-DP, L-4=2.21) is an ineffective zone to make the last pass. 
Table 3. Lag sequential analysis between the given categories of the Consequence of completion dimension and the target behaviours corresponding to the Zone dimension. In the left column are the given behaviours

\begin{tabular}{|c|c|c|c|c|c|c|}
\hline & $\mathrm{OO}$ & $\mathrm{OZ}$ & OP & DO & DZ & $\mathrm{DP}$ \\
\hline MS & L0 (3.01) & $\begin{array}{l}\text { L-1 (2.59) } \\
\text { L0 (2.57) }\end{array}$ & $\frac{\mathrm{L}-1(-2.86)}{\mathrm{L} 0(-4.38)}$ & & & \\
\hline $\mathrm{RF}$ & & L0 (-2.9) & L0 (3.96) & L-2 (2.10) & & \\
\hline FA & & & & & L-3 (2.18) & $\begin{array}{l}\text { L-5 (1.97) } \\
\text { L-4 (2.21) }\end{array}$ \\
\hline DB & & $\underline{\mathrm{L}-1}(-2.12)$ & L-1 (2.42) & & L-2 (2.80) & $\begin{array}{l}\text { L-3 }(2.41) \\
\text { L-1 (2.26) }\end{array}$ \\
\hline A1 & & $\begin{array}{l}\mathrm{L}-1(-2.41) \\
\mathrm{L} 0(-2.02)\end{array}$ & $\begin{array}{l}\text { L-1 (2.95) } \\
\text { L0 (2.77) }\end{array}$ & & L-2 (2.52) & L-5 (2.11) \\
\hline
\end{tabular}

Mistake (MS); Received foul (RF); Foul in attack (FA); Direct block (DB); Basket and Foul (A1). Offensive outside (OO); Offensive zone (OZ); Offensive paint (OP); Defensive Outside (DO); Defensive zone (DZ); Defensive paint (DP). Negative adjusted residuals that imply inhibitory relationships between associated behaviours are underlined.

An association has been detected (Table 4) between the Completion type and Classification level dimensions of the player who makes the shot $\left(\chi^{2}=56.86 ; \mathrm{df}=30 ; \mathrm{p}<0.01\right)$. From the results shown in Table 4 it can be deduced that when the shot is made by the $\mathrm{H} 45$ classification level player, there is an association with the shot ending in the basket plus an additional shot (A1-H45, LO=2.79). When a player of classification level H1O shoots there is an inhibition relationship with scoring (SC-H1O, $\mathrm{LO}=-2.08)$; and of association with failed shot $(\mathrm{MS}-\mathrm{H} 1 \mathrm{O}, \mathrm{LO}=\mathbf{2 . 1 2}$ ) or violation (VI-H1O, LO=5.01). Furthermore, the association has been detected that when the H2O classification level player shoots, he receives a direct block (TP-H2O; Lo=3.00). Also in lag-1 $\left(\chi^{2}=60.24 ; \mathrm{df}=30 ; \mathrm{p}<0.001\right)$ and in lag $-3\left(\chi^{2}=49.36\right.$; $\mathrm{df}=30 ; \mathrm{p}<0.001)$ an association has been detected between the completion type and the classification level dimensions of the player that performs the action corresponding to that lag.

Table 4. Lag sequential analysis between the given categories of the Consequence of completion dimension and the target behaviours corresponding to the Classification level dimension.

\begin{tabular}{|c|c|c|c|c|}
\hline & Class 1.0 & Class 2.0 & Class 3.0 & Class 4.5 \\
\hline \multirow[t]{3}{*}{ Score } & $\mathrm{L}-3(-2.61)$ & & L-3 (2.26) & \\
\hline & $\mathrm{L}-1(-2.39)$ & & & \\
\hline & $\underline{\mathrm{L} 0}(-2.08)$ & & & \\
\hline \multirow[t]{4}{*}{ Mistake } & L-3 (2.72) & $\underline{\mathrm{L}-4}(-2.02)$ & $\underline{\mathrm{L}-3}(-1.98)$ & \\
\hline & L-2 (2.21) & & & \\
\hline & L-1 (2.38) & & & \\
\hline & L0 (2.12) & & & \\
\hline \multirow{2}{*}{ Received foul } & & & & L-3 (2.82) \\
\hline & & & & L-2 (3.03) \\
\hline \multirow[t]{2}{*}{ Violation } & L-1 (5.15) & & L-5 (3.18) & L-3 (3.34) \\
\hline & L0 (5.01) & & L-4 (2.4) & L-2 (3.47) \\
\hline \multirow[t]{2}{*}{ Direct block } & & L-1 (3.05) & & \\
\hline & & L0 (3.00) & & \\
\hline \multirow[t]{2}{*}{ Basket and Foul } & & & & L-1 (2.76) \\
\hline & & & & L0 (2.79) \\
\hline
\end{tabular}

Negative adjusted residuals that imply inhibitory relationships between associated behaviours are underlined.

If the last reception is made by a player of classification level $\mathrm{H} 45$ there is an association with a scored shot plus additional shot $(\mathrm{A} 1-\mathrm{H} 45, \mathrm{~L}-1=2.76)$. If the last pass is made by a player of classification level $\mathrm{H} 45$, an association with favourable (RF-H45; L-2=3.03; RF$\mathrm{H} 45, \mathrm{~L}-3=2.82$ ) and unfavourable (VI-H45, L-2=3.47; VI-H45, L-3=3.34) consequences has been detected. If the reception before the last pass is made by $\mathrm{H}_{30}$ classification level 
players, there is an association with scoring the shot ( $\mathrm{SC}-\mathrm{H} 3 \mathrm{O}, \mathrm{L}-3=2.26)$, and inhibition with missing the shot (MS-H30, L-3=-1.98). This inhibition ratio with a missed shot also appears in lag-4 in H2O classification level players (MS-H2O, L-4=-2.02). In H1O classification level players, ineffective situations have been detected in relation to the last reception (SC-H1O, L-1=-2.39; MS-H10; L-1=2.38; VI-H10, L-1=5.15; DB-H2O, L-1=3.05), the last pass (MS-H1O, L-2=2.21), and the reception before the last pass (MS-H1O, L-3=2.72; SC-H10, L-3=-2.61).

Regarding the analysis of the Start of the sequence dimension (see Table 5) and compared to the effective sequences, in lag -5 the relationship of the defensive field with the efficiency (SC-DC, L-5=2.41; MS-DC, L-5=-2.63). This effectiveness is maintained in the sequences starting at defensive lateral left (SC-DLL, L-5=2.04), defensive lateral right (RFDLR, L-5=2.49) and the defensive paint (A1-DP, L-5=2.11). Although the start of the sequence in the defensive paint also shows an association relationship with a foul in attack (FA-DP, L-5 =1.97). Regarding the ineffective sequences, associations with the defensive and offensive rebound have been detected (FA-DR, L-5=2.14; MS-OR, L-5=2.26). Effective sequences have also been characterized from the significant adjusted residuals corresponding to lag -3 , in which the sequence has a single pass and begins with a recovery (SC-BR, L-3=2.20; MS-BR, L-3=-2.41) or a rebound (MS-DR, L-3=-2.13) although an activation relationship has also been detected when the shot is directly blocked (DB-DR, L$3=2.16)$.

Table 5. Lag sequential analysis between the categories given of the dimension Consequence of the shot and the behaviours target corresponding to the dimensions Game action and Start of the sequence that ends in shot. In the left column are the given behaviours

\begin{tabular}{|c|c|c|c|c|c|c|c|}
\hline & BR & $\mathrm{OR}$ & DR & $\mathrm{P} 1$ & $\mathrm{R} 1$ & $\mathrm{R} 2$ & $\mathrm{SH}$ \\
\hline $\mathrm{SC}$ & L-3 (2.20) & & & $\frac{\mathrm{L}-4(-}{2.64)}$ & $\frac{\mathrm{L}-3(-}{2.22)}$ & $\underline{\mathrm{L}}-1(-1.97)$ & L-4 (2.31) \\
\hline MS & $\underline{\mathrm{L}-3}(-2.41)$ & L-5 (2.26) & $\frac{\mathrm{L}-3(-}{2.13)}$ & $\overline{\mathrm{L}-4}(2.67)$ & $\overline{\mathrm{L}-3}(2.55)$ & $\frac{\mathrm{L}-5(-2.5)}{\mathrm{L}-1(2.07)}$ & $\frac{\mathrm{L}-4(-}{3.02)}$ \\
\hline FA & & & L-5 (2.14) & & & & \\
\hline DB & & & L-3 (2.16) & & & & \\
\hline
\end{tabular}

Score (SC); Mistake (MS); Foul in attack (FA); Direct block (DB). In the top row are the target behaviours: Ball recovered (BR); Offensive rebound (OR); Defensive rebound (DR); Penultimate pass (P1); Penultimate reception (R1); Last reception (R2); Shot (SH). Negative adjusted residuals that imply inhibitory relationships between associated behaviours are underlined.

\section{Discussion}

The objective of this study was to analyse the construction and effectiveness of the offensive sequences that led to a shot of the USA men's wheelchair basketball team and take into account the classification level of the player who performs the technical-tactical action. The observation instrument used in this study was used for the analysis of the game and the effectiveness in elite basketball (Alsasua et al., 2019; Fernández et al., 2009) and was adapted for wheelchair basketball. The adaptation carried out made it possible to include the issue of classification levels in the study. The influence on performance from classification has been previously studied (Gómez et al., 2014; Molik et al., 2009; Vanlandewijck et al., 2004), but has not been incorporated into the technical-tactical analysis of the game.

Methodologically, this work constitutes an example of the possibilities that lag sequential analysis (Bakeman, 1978), within observational methodology (Anguera, 1979), contributes to the match analysis of wheelchair basketball. Next, we proceed to the interpretation of the statistically significant adjusted residuals, which provide more relevant information on the analysis of the game, starting with lag o or co-occurrence. Then we address the retrospective diachronic relationships in relation to the shot. As a reminder, lag 
o refers to the co-occurrence in the multi-event corresponding to Completion type of the sequence; and that lag -1 is related to the reception prior to the shot, lag -2 with the last pass, lag -3 with the penultimate reception, and lag -4 with the penultimate pass.

\section{Lag 0 or co-occurrence}

Regarding the proxemic analysis (laterality dimension) of the adjusted residuals corresponding to lag $\mathrm{o}$, effective and ineffective behaviours were detected. If attention is paid to effective sequences, the greater effectiveness of the right bottom offense agrees with results obtained in ambulant basketball that present it as one of the most effective places to take a shot, although other authors consider the left bottom offense to be more effective than the right (Alsasua et al., 2019; Fernández et al., 2009; García et al., 2013). Regarding ineffective sequences, the presence of the right lateral contrasts with Gómez and colleagues (2015) for whom it appears as an effective shot area; while the use of the centre as an ineffective shot area is reflected in several running basketball studies (Fernández et al., 2009; Nunes et al 2015; Alsasua et al., 2019).

Continuing with the proxemic analysis (zone dimension), our results coincide with those of several ambulant basketball studies of the most effective and most used place to shoot (Alsasua et al., 2019; Fernández et al., 2009; Gómez et al., 2013; Serna et al., 2017) coincides in wheelchair basketball. The results of Vanlandewijck et al. (2004), who point to offensive paint as the most effective shot site. Regarding ineffective sequences, our results coincide with those obtained in running basketball studies where shots from the offensive outside or from the offensive intermediate zone are also presented as ineffective and infrequent, especially the intermediate zone (Alsasua et al., 2019; Fernández et al., 2009; Gómez et al., 2013). Yet, Gómez and colleagues (2015) did obtain results in which the frequency of shots from the outside zone was close to those made from the paint. In wheelchair basketball, these zones (offensive outside and offensive intermediate) are also characterized as less effective, but with a greater use of shooting from the intermediate zone, which in some classification levels (between $\mathrm{H} 10$ and H25) becomes the area with the highest use for shooting (Vanlandewijck et al., 2004).

Next, we proceed to the discussion of the classification level of the player making the shot. In addition to the fact that significant differences have been found in the contingency table that incorporates the Completion type and Classification level dimensions of the player who makes the shot, the analysis of the adjusted residuals by cells clearly shows us the relationship of the classification levels with the effectiveness in wheelchair basketball. Specifically, when the shot is made by the player with the least limitations ( $\mathrm{H} 45)$, there is an association with the shot ending in a score plus an additional shot; which is in tune with the results of Pérez-Tejero and Pinilla (2015) and Skučas and colleagues (2009) who found that these players are the ones that receive the most fouls, they make the most shots and with the most success. On the contrary, when the functional difficulties of the shooting player are greater (H1O) there is a relationship and inhibition of the possibility of scoring the shot; and an association with a failed shot or violation. This lower effectiveness on the part of these players agrees with the results of Grashchenkova and colleagues (2018) who pointed out these players as the ones with the fewest shots made per game and the least successful ones with these shots. Related to this limited degree of mobility, an association has been detected in which the player H2O makes a shot and receives a direct block.

\section{Retrospective lags}

Next, the results corresponding to the diachronic relationships are interpreted. Regarding the results corresponding to the proxemical analysis of the Laterality dimension, those that incorporate the use of the right bottom in the reception prior to shooting as well 
as the reception prior to the last pass have been characterized as effective sequences. And as ineffective sequences those that include in the offensive bottom left the last reception, the penultimate pass, and the last pass. These results corresponding to the Laterality dimension are in agreement with results obtained in ambulant basketball by authors such as Serna and colleagues (2017) and Alsasua and colleagues. (2018). On the other hand, those sequences in which the last reception takes place in the offensive centre have been characterized as ineffective, in line with the results that ambulant basketball studies where they present the use of the offensive centre as an ineffective place for the shot (Fernández et al., 2009; Nunes et al 2015; Alsasua 2019). Effective and ineffective sequences in which the defensive field is present have been characterized. Effective sequences were found on the defensive right side; the defensive centre; and the defensive bottom left. And ineffective sequences, in the defensive bottom left, the defensive lateral right, the defensive lateral left and the defensive bottom right. This presence of situations prior to shooting on the defensive field is related to a counterattack or fast attack that fits into the sequences of between 6 and 10 seconds, which Pérez-Tejero and colleagues (2020) characterized as the most frequent in wheelchair basketball.

Regarding the retrospective analysis of the proxemic dimension zone, and regarding the last reception (lag -1) it is again pointed out that the offensive paint is an effective place for shooting, while the intermediate zone is a usually ineffective place. Both characterizations agree with the results obtained in lag $o$ and with the results obtained in studies of elite ambulant basketball that present the offensive paint as the most effective zone and the intermediate area as an ineffective zone and little used for shooting (Fernández et al., 2009; Gómez et al., 2013; Gómez et al., 2014; Serna et al., 2017; Alsasua et al., 2019). In contrast to this reduced presence in ambulant basketball, in our study an important presence of the intermediate zone is observed aligns with the results of Vanlandewijck et al. (2004). Again, with the proxemical analysis of the defensive field, but in this case linked to the zone dimension, the relevance in wheelchair basketball of short duration sequences and counterattack is evident (Pérez-Tejero et al., 2020). Specifically, it has been detected that the presence of the defensive outside favours effective counterattack situations, like what happens in ambulant basketball (Ortega \& Gómez, 2009); whereas the defensive intermediate zone presents effective and ineffective situations; and defensive paint is revealed as an ineffective zone for initiating a counterattack coinciding with the results of Refoyo and colleagues (2009) in ambulant basketball.

Statistically significant differences have also been found in the contingency table that incorporates the Completion type dimensions and the classification level of the player that performs the action corresponding to lags -1 and -3 . The analysis of the residuals adjusted by cells of the retrospective lags deepens in the relationship of the classification levels with effectiveness in wheelchair basketball. Thus, if the last reception (lag 1) is developed by a player with less functional limitation, there is an association with a scored shot plus an additional shot. This circumstance is directly related to the effectiveness shown in the completion by players with less functional limitations. The relationship with the efficacy of H45 in situations of the last pass does not seem so clear. Pérez-Tejero and Pinilla (2015) conclude that players with $\mathrm{H} 40$ and $\mathrm{H} 45$ classification levels, grouped by the authors in a single category, are the ones that make the most assists (passes finished in a scored shot). Grashchenkova and colleagues (2018) reported the players with $\mathrm{H} 45$ classification level registered the most assists, although slightly outnumbered by the players with the $\mathrm{H}_{40} \mathrm{O}$ classification level.

In lag -3 , it was detected that the reception prior to the last pass by players with an $\mathrm{H}_{30}$ classification level, has an activation relationship with a scored shot, and inhibition with a 
shot failed; this inhibition with a missed shot also appears at lag -4 in players with $\mathrm{H} 2 \mathrm{O}$ classification level. Regarding the effectiveness of H2O and H3O players, Pérez-Tejero and Pinilla (2015) found no significant differences between the two classification and bounces, shots, scoring and assists metrics. Ineffective situations have also been characterized in the present study, in which players with less functionality intervene (Grashchenkova et al., 2018; Pérez-Tejero et al., 2015; Skucas et al., 2009), both in relation to the last reception, as in the last pass, and in the reception prior to the last pass. This circumstance is in agreement with the results of Pérez-Tejero and Pinilla (2015) in relation to the lower number of assists made by players with greater functional limitations.

Regarding the retrospective analysis of the dimension Start of the sequence, the results show the relationship of the defensive field with efficacy present in fast and counterattack sequences (Pérez-Tejero et al., 2020). This efficacy is not as clear from the defensive paint. Relevant associations related to ineffective sequences have also been detected, related to the defensive and offensive rebound in this regard, Ibáñez et al. (2009) already clarified that in ambulant basketball the offensive rebound was an effective situation to shoot directly to the basket. Effective sequences have also been characterized in sequences constituted by a single pass and begins with a recovery or a rebound. These single pass situations are related to the counterattack and the usual fast sequences in wheelchair basketball (Pérez-Tejero et al., 2020). In ambulant basketball, recoveries and defensive rebounds in this order are the most common forms of initiation of counterattacks (Refoyo et al., 2009), and are more effective when they initiate recovery (Lorenzo et al., 2010; Sampaio et al., 2010).

The main limitation of this work is that it is an idiographic study that analysed the 2016 Paralympic champion, the USA men's Wheelchair Basketball team. It is our intention in future works to also analyse the construction and effectiveness of the offensive sequences that lead to a shot of the Paralympic runner-up and establish a comparative analysis between champion and runner-up, paying special attention to the performance of the players based on their classification level. This work, in addition to showing the possibilities of the lag sequential analysis within observational methodology, makes a novel contribution to wheelchair basketball, as an analysis of the shooting situation (lag o or co-occurrence) and previous actions (prior reception to the shot, last pass, reception before the last pass, penultimate pass, and reception before the penultimate pass), depending on the classification level of the player who performed the action.

\section{Perspectives}

The results allow us to delve into the specificity of the game of this sport, having detected similarities and differences with running basketball, and show relevant evidence regarding the preparation of training and competitions by the technicians of this sport. Concluding in a summarized way, the sequences that have been shown to be effective: end with a shot from the right bottom offense or from the offensive painting. Concluding in a summarized way, the sequences that have been shown to be effective: end with a shot from the right bottom or from the painting; shots made by players with less functional limitations; those that incorporate the use of the right bottom in the reception prior to shooting as well as in the reception prior to the last pass; short duration sequences and counterattacks; and sequences consisting of a single pass and that begin with a recovery or a rebound. The sequences that have been shown to be ineffective: shot from the right lateral and the centre or from the offensive outside or from the offensive intermediate zone; sequences that end with shooting by players with the greatest functional limitations; the sequences in which the last reception takes place in the offensive centre; and sequences in which players with greater functional difficulties perform the last reception, the last pass, and the reception prior to the last pass. The results of the present work have allowed us to characterize the construction of the 
offensive sequences that achieve a shot, both effective and ineffective, and taking into consideration the classification level of the player performing the action.

\section{Author affiliations: (will be blinded by editors for review process)}

$1 \quad$ Department of Educational Sciences. University of La Rioja, Spain. ralsasua23@hotmail.com

2 Department of Education in Sciences. University of Burgos; Department of Physical Education and Sport.

Pontifical University of Salamanca. Spain. rarroyode@upsa.es

3 Department of Educational Sciences. University of La Rioja, Spain. xabier.arana@unirioja.es

4 Department of Educational Sciences. University of La Rioja, Spain. daniel.lapresa@unirioja.es

5 Faculty of Psychology, Institute of Neurosciences, University of Barcelona, Barcelona, Spain.

tanguera@ub.edu

* Correspondence: daniel.lapresa@unirioja.es; Tel.: +34-941-299-282

Author Contributions: Conceptualization: RA, RA, JA, DL, M.T.A; Methodology: RA, RA, JA, DL, M.T.A; Data Analysis; JA, DL, M.T.A; Write-up: RA, RA, JA, DL, M.T.A; Reviewing: RA, RA, JA, DL, M.T.A.

Funding: This research received no external funding

Acknowledgments: The authors gratefully acknowledge the support of a Spanish government subproject Integration ways between qualitative and quantitative data, multiple case development, and synthesis review as main axis for an innovative future in physical activity and sports research [PGC2018-098742-B-C31] (20192021) (Ministerio de Ciencia, Innovación y Universidades / Agencia Estatal de Investigación / Fondo Europeo de Desarrollo Regional), that is part of the coordinated project New approach of research in physical activity and sport from mixed methods perspective (NARPAS_MM) [SPGC201800X098742CVo]. In addition, authors thanks the support of the Generalitat de Catalunya Research Group, GRUP DE RECERCA I INNOVACIÓ EN DISSENYS (GRID). Tecnología i aplicació multimedia i digital als dissenys observacionals [Grant number 2017 SGR 1405].

Conflicts of Interest: The authors declare no conflict of interest.

\section{References}

Alsasua, R., Lapresa, D., Arana, J., Anguera, M.T., \& Garzón, B. (2018). Successful and unsuccessful offensive sequences ending in a shot in professional and elite under-16 basketball. Journal of Human Kinetics, 64(1), 147-159. https://doi.org/10.1515/hukin-2017-0191

Alsasua, R., Lapresa, D., Arana, J., \& Anguera, M.T. (2019). A log-linear analysis of efficiency in elite basketball applied to observational methodology. International Journal of Sports Science \& Coaching, 14(3), 363-371, https://doi.org/10.1080/24748668.2018.1475195

Anguera, M.T. (1979). Observational typology. Quality \& Quantity. European-American Journal of Methodology, 13(6), 449-484.

Anguera, M.T. (2003). La observación [The observation]. En C. Moreno Rosset (Ed.), Evaluación psicológica. Concepto, proceso y aplicación en las áreas del desarrollo y de la inteligencia (pp. 271-308). Madrid: Sanz y Torres.

Anguera, M.T., Blanco-Villaseñor, A., Hernández-Mendo, A., \& Losada, J.L. (2011). Diseños observacionales: ajuste y aplicación en psicología del deporte [Observational designs: Their suitability and application in sports psychology]. Cuadernos de Psicología del Deporte, 11(2), 63-76.

Anguera, M.T., Portell, P., Hernández-Mendo, A., Sánchez-Algarra, P., \& Jonsson, G.K. (2021). Diachronic analysis of qualitative data. In A.J. Onwuegbuzie and B. Johnson (Eds.), Reviewer's Guide for Mixed Methods Research Analysis. (pp. 125-139). London: Routledge.

Antonelli, C., Hartz, C., Silva, S., \& Moreno, M.A. (2020). Effects of inspiratory muscle training with progressive loading on respiratory muscle function and sports performance in highperformance wheelchair basketball athletes: A randomized clinical trial. International Journal of Sports Physiology and Performance, 15, 238-242. https://doi.org/10.1123/ijspp.2018-0979

Arana, J., Lapresa, D., Anguera, M.T., \& Garzón, B. (2016). Ad hoc procedure for optimising agreement between observational records. Anales de Psicología, 32(2), 589-595. http://dx.doi.org/10.6018/analesps.32.2.213551

Bakeman, R. (1978). Untangling streams of behavior: Sequential analysis of observation data. In G.P. Sackett (Ed.), Observing Behavior (Vol. 2, pp. 63-78). Baltimore: University of Park Press.

Bakeman, R. \& Quera, V. (1995). Analyzing interaction: Sequential analysis with SDIS and GSEQ. Cambridge: Cambridge University Press.

Bakeman, R., \& Gottman, J.M. (1986). Observing interaction: An introduction to sequential analysis. New York: Cambridge University Press.

Bakeman, R., \& Quera, V. (2011). Sequential analysis and observational methods for the behavioral sciences: Cambridge University Press. 
Barboza, B., Oliveira, M., Lambert, E., Werle, E., Marta, S., \& Greguol, M. (2019). Does the type of disability influence salivary cortisol concentrations of athletes in official wheelchair basketball games? International Journal of Sports Science \& Coaching, 14(4) 507-513. https://doi.org/10.1177/1747954119850301

Cohen, J. (1960). A coefficient of agreement for nominal scales. Educational and Psychological Measurement, 20, 37-46. https://doi.org/10.1177/001316446002000104

Conners, R.T., Elliott, J.M., Kyle, D.L., Solomon, S., \& Whitehead, P.N. (2020). Physiological responses of youth players during wheelchair basketball games. European Journal of Adapted Physical Activity, 13, 9; https://doi.org/10.5507/euj.2020.005

de Witte, A.M.H., Berger, M.A.M., Hoozemans, M.J.M., Veeger, H.E.J., \& van der Woude, L.H.V. (2017). Effects of offense, defense, and ball possession on mobility performance in wheelchair basketball. Adapted Physical Activity Quarterly, 34(4), 382-400. https://doi.org/10.1123/apaq.2016-0125

de Witte, A.M.H., Hoozemans, M.J.M., Berger, M.A.M., van der Slikke, R.M., van der Woude, L.H., \& Veeger, D. (2018). Development, construct validity and test-retest reliability of a field-based wheelchair mobility performance test for wheelchair basketball. Journal of Sports Sciences, 36(1), 23-32. https://doi.org/10.1080/02640414.2016.1276613

de Witte, A.M.H., Hoozemans, M.J.M., Berger, M.A.M., Veeger, H.E.J., \& van der Woude, L.H.V. (2016). Do field position and playing standard influence athlete performance in wheelchair basketball? Journal of Sports Sciences, 34(9), 811-820. https://doi.org/10.1080/02640414.2015.1072641

Fernández, J., Camerino, O., Anguera, M.T., \& Jonsson, G.K. (2009). Identifying and analyzing the construction and effectiveness of offensive plays in basketball by using systematic observation. Behavior Research Methods, 41(3), 719-730. http://dx.doi.org/10.3758/BRM.41.3.719

Feter, N., Calonego, C., Cavanhi, A.C., \& del Vecchio, F.B. (2018). Wheelchair basketball: fitness and quality of life. European Journal of Adapted Physical Activity, 11(1): 5 . https://doi.org/10.5507/euj.2018.001

Francis, J., Owen, A., \& Peters, D.M. (2019a). A new reliable performance analysis template for quantifying action variables in elite men's wheelchair basketball. Frontiers in Psychology, 1O(16). https://doi.org/10.3389/fpsyg.2019.00016

Francis, J., Owen, A., \& Peters, D.M. (2019b). Making every “point” count: identifying the key determinants of team success in elite men's wheelchair basketball. Frontiers in Psychology, 1O(1431). https://doi.org/10.3389/fpsyg.2019.01431.

Gabin, B., Camerino, O., Anguera, M.T., \& Castañer, M. (2012). Lince: multiplatform sport analysis software. Procedia-Social and Behavioral Sciences, 46, 4692-4694. https://doi.org/10.1016/j.sbspro.2012.06.320

Galea, I., Dulceanu, C., \& Ungureanu, O. (2018). Aspects of the relationship between heart rate and precision of throwing in wheelchair basketball. Preliminary study. Arena-Journal of Physical Activities, 7, 21-29.

García, J., Ibáñez, S.J., Martínez de Santos, R., Leite, N., \& Sampaio, A.J. (2013). Identifying Basketball Performance Indicators in Regular season and Playoff Games. Journal of Human Kinetics, 36, 161-168. https://doi.org/10.2478/hukin-2013-0016

Gómez, M.A., Alarcón, F, \& Ortega, E. (2015). Analysis of shooting effectiveness in elite basketball according to match status. Revista de Psicología del Deporte, 24 (Suppl 1), 37-41.

Gómez, M.A., Lorenzo, A., Ibáñez. S.J., \& Sampaio, J. (2013). Ball possession effectiveness in men's and women's elite basketball according to situational variables in different game periods, Journal of Sports Sciences, 31(14), 1578-687. https://doi.org/10.1080/02640414.2013.792942

Gómez, M.A., Pérez, J., Molik, B., Szyman, R. J., \& Sampaio, J. (2014). Performance analysis of elite men's and women's wheelchair basketball teams. Journal of Sports Sciences, 32(11), 10661075. https://doi.org/10.1080/02640414.2013.879334

Grashchenkova, Z., Mishyn, M.K., Okopnyy, A., Pityn, M., \& Hnatchuk, Y. (2018). Peculiar features of competitive activity of qualified wheelchair basketball players. Journal of Physical Education and Sport, 18, 2331. https://doi.org/10.7752/jpes.2018.04352

Hollander, K., Kluge, S., Glöer, F., Riepenhof, H., Zech, A. \& Junge, A. (2020). Epidemiology of injuries during the wheelchair Basketball world Championships 2018: a prospective cohort study. Scandinavian Journal of Medicine \& Science in Sport, 3O(1), 199-207. https://doi.org/10.1111/sms.13558

Ibáñez, S.J., García, J., Feu, S., Parejo, I., \& Cañadas, M. (2009). La eficacia del lanzamiento a canasta en la NBA: Análisis multifactorial [Shot efficacy in the NBA: A multifactorial analysis]. Cultura, Ciencia y Deporte, 10, 39-47.

International Wheelchair Basketball Federation. (2014). Classification Manual basketball player in a wheelchair. IWBF. Canada. 
International Wheelchair Basketball Federation. (2017). Official Wheelchair Basketball Rules. IWBF. Switzerland.

Landis, J.R. \& Koch, G.G. (1977). The measurement of observer agreement for categorical data. Biometrics, 33, 159-174. https://doi.org/10.2307/2529310

Lapresa, D., Arana, J., Anguera, M.T., \& Garzón, B. (2013). Comparative analysis of the sequentiality using SDIS-GSEQ and THEME: a concrete example in soccer. Journal of Sports Sciences, 31(15), 1687-1695. http://dx.doi.org/10.1080/02640414.2013.796061

Lapresa, D., Santesteban, G., Arana, J., Anguera, M.T. \& Aragón, S. (2017). Observation System for Analyzing Individual Boccia BC3. Journal of Developmental and Physical Disabilities, 29(5), 721-734. https://doi.org/10.1007/s10882-017-9552-2

Lorenzo, A., Gómez, M.A., Ortega, E., Ibáñez, S.J., \& Sampaio, J. (2010). Game related statistics which discriminate between winning and losing under-16 male basketball games. Journal of Sports Science and Medicine, 9, 664-668.

Maksym, M., Oleg, K., Viacheslav, M., Larysa, T., Zhanna, G., Olena, T., ... \& Iryna, P. (2018). Problems and features of technique in the development of coordination abilities of players specializing in wheelchair basketball. Journal of Physical Education and Sport, 18, 1016-1020. https://doi.org/10.7752/ipes.2018.s2150

Marjolaine, A., Weissland, T., Vallier, J.M., Pradon, D., Watelain, E., \& Faupin, A. (2018). Effects of synchronous versus asynchronous push modes on performance and biomechanical parameters in elite wheelchair basketball. Sports Engineering, 21(1), 43-51.

Marszałek, J., Gryko, K., Kosmol, A., Morgulec-Adamowicz, N., Mróz, A., \& Molik, B. (2019) Wheelchair basketball competition heart rate profile according to players' functional classification, tournament level, game type, game quarter and playing time. Frontiers in Psychology, 1O(773). https://doi.org/10.3389/fpsyg.2019.00773

Mason, B.S., van der Slikke, R.A., Hutchinson, M.J., Berger, M.M., \& Goosey-Tolfrey, V.L. (2018). The effect of small-sided game formats on physical and technical performance in wheelchair basketball. International Journal of Sports Physiology and Performance, 13(7), 891-896. https://doi.org/10.1123/ijspp.2017-0500

Molik, B., Kosmol, A., Morgulec-Adamowicz, N., Laskin, J.J., Jezior, T., \& Patrzałek, M. (2009). Game efficiency of elite female wheelchair basketball players during world championships (Gold Cup) 2006. European Journal of Adapted Physical Activity, 2(2), 26-38. https://doi.org/10.5507/euj.2009.007

Molik, B., Laskin, J.J., Golbeck, A.L., Kosmol, A., Rekowski, W., Morgulec-Adamowicz, N., ... \& Gómez, M.A. (2017). The international wheelchair basketball federation's classification system: The participants' perspective. Kinesiology, 49(1), 117-126. https://doi.org/10.26582/k.49.1.1

Nunes, H., Iglesias, X., Daza, G., Irurtia, A., Caparrós, T., \& Anguera M.T. (2015). The influence of pick and roll in attacking play in top-level basketball. Cuadernos de Psicología del Deporte, 16(1), 129-142.

Ortega, E., \& Gómez, M.A. (2009). Metodología observacional en baloncesto de formación [Observational methodology in grassroots basketball]. Murcia: Diego Marín Librero-Editor.

Palau, J., Martínez J.O., García M.A., \& Ríos, M. (2011). Modalidades deportivas adaptadas a las personas con discapacidad física de la Federación Española de Deportes para Personas con Discapacidad Física [Sports modalities adapted for people with physical disabilities by the Spanish Federation of Sports for People with Physical Disability]. In J. Palau (Coord.), Deportistas sin adjetivos. El deporte adaptado a las personas con discapacidad física (251706). Madrid: Consejo Superior de Deportes y Comité Paralímpico Español.

Pérez-Tejero, J., \& Pinilla, J. (2015). Rendimiento del jugador de baloncesto en silla de ruedas según la estadística de juego [Wheelchair basketball player performance by game statistics]. Cuadernos de Psicología del Deporte, 15(3), 231-236. https://doi.org/10.4321/s157884232015000300027

Pérez-Tejero, J., Pinilla, J., Aceituno, J., \& Sampedro, J. (2020). Análisis temporal y reglamentario en el baloncesto en silla de ruedas de alto nivel: conclusiones para el entrenamiento. [Time and reglamentary analysis during high level wheelchair basketball competition: training conclusions]. SPORT TK-Revista EuroAmericana de Ciencias del Deporte, 9(1), 7-14. https://doi.org/10.6018/sportk.412431

Peters, J., Rice, I., \& Bull, T. (2020). Exploring the influence of wheelchair-user interface and personal characteristics on ischial tuberosity peak pressure index and gradient in elite wheelchair basketball players. Adapted Physical Activity Quarterly, 37, 56-71. https://doi.org/10.1123/apaq.2019-0030

Qasim, S., Telfah, Y., \& Haddad, Y. (2019). Physical self-esteem of wheelchair basketball players. Acta Gymnica, 49(1), 3-9. https://doi.org/10.5507/ag.2018.025 
Refoyo, I., Romaris, I.U., \& Sampedro, J. (2009). Analysis of men's and women's basketball fastbreaks. Revista de Psicología del Deporte, 18(3), 439-444.

Sampaio, J., Lago, C. \& Drinkwater, E.J. (2010). Explanations for the United States of America's dominance in basketball at the Beijing Olympic Games (2008). Journal of Sports Sciences, 28(2), 147-152. https://doi.org/10.1080/02640410903380486

Sasadai, J., Maeda, N., Shimizu, R., Kobayashi, T., Sakai, S., Komiya, M., \& Urabe, Y. (2020). Analysis of team-sport wheelchair falls during the Rio 2016 Summer Paralympic Games: a video-based cross-sectional observational study. BMJ Open, 10: e033088. https://doi.org/10.1136/bmjopen-2019-033088

Serna, J., Muñoz, V., Hileno, R., Solsona, E., \& Sáez, U. (2017). T-Patterns initiated with ball screen or one-on-one in basketball. Revista de Psicología del Deporte, 26(3), 81-86.

Skučas, K., Stonkus, S., Molik, B., \& Skučas, V. (2009). Evaluation of wheelchair basketball skill performance of wheelchair basketball players in different game positions. Education, Physical Training, Sport, 75, 65-69.

Tarrago, R., Iglesias, X., Lapresa, D., Anguera, M.T., Ruiz-Sanchís, L. \& Arana, J. (2017). Analysis of diachronic relationships in successful and unsuccessful behaviors by world fencing champions using three complementary techniques. Anales de Psicología, 33(3), 471-485. https://doi.org/10.6018/analesps.33.3.271041

Troyano, O.A., Almeida, N., \& De Barros F.A. (2018). Relação entre número de passes e assistências na liga nacional de basquetebol: chave para o sucesso? [Relationship between pass and assists production in the national basketball league: key to success?] Revista Brasileira de Prescrição e Fisiologia do Exercício, 79(12), 917-925.

Vanlandewijck, Y.C., Evaggelinou, C., Daly, D., Van Houtte, S., Verellen, J., Aspeslagh, V.,... Zwakhoven, B. (2003). Proportionality in wheelchair basketball classification. Adapted Physical Activity Quarterly, 20, 369-380. https://doi.org/10.1123/apaq.20.4.369

Vanlandewijck, Y.C., Evaggelinou, C., Daly, D.J., Verellen, J., Houtte, S.V., Aspeslagh, V., ... Zwakhoven, B. (2004). The relationship between functional potential and field performance in elite female wheelchair basketball players. Journal of Sports Sciences, 22(7), 668-675. https://doi.org/10.1080/02640410310001655750

Yeatts, P.E., Davis, R., Oh, J., \& Hwang, G.Y. (2019). The Impact of Game Outcome on Affect of Military Wheelchair Basketball Players. Adapted Physical Activity Quarterly, 36(3), 378-387. https://doi.org/10.1123/apaq.2018-0164

Zacharakis, E. (2020). The effect of upper limb characteristics on palm strength, anaerobic power, and technical skills of wheelchair basketball players of varying classification. Journal of Physical Education \& Sport, 20(2), 584-591. https://doi.org/10.7752/jpes.2020.02086

(C) 2021 by the authors. Submitted for possible open access publication under the terms and conditions of the Creative Commons Attribution (CC BY) license (http://creativecommons.org/licenses/by/4.o/). 